\title{
FORMAÇÃO DE PROFESSORES INDÍGENAS: DESAFIOS E PERSPECTIVAS A PARTIR DO CURRÍCULO DO CURSO DE PEDAGOGIA INTERCULTURAL INDÍGENA
}

FORMACIÓN DE PROFESORES INDÍGENAS: RETOS Y PERSPECTIVAS DESDE EL CURRÍCULO DEL CURSO DE PEDAGOGÍA INTERCULTURAL INDÍGENA

TRAINING OF INDIGENOUS TEACHERS: CHALLENGES AND PERSPECTIVES FROM THE CURRICULUM OF THE INDIGENOUS INTERCULTURAL PEDAGOGY

COURSE

DOI: 10.22481/rbba.v1i02.7767

Adria Simone Duarte de Souza Universidade do Estado do Amazonas, Amazonas, Brasil ORCID: https://orcid.org/0000-0002-3234-4882 ID Lattes: http://lattes.cnpq.br/7915521365617792 Endereço eletrônico: asduarte@uea.com.br

Celia Aparecida Bettiol Universidade do Estado do Amazonas, Amazonas, Brasil ORCID: http://orcid.org/0000-0002-0313-494X

ID Lattes: http://lattes.cnpq.br/6935670235651644 Endereço eletrônico: caparecida@ uea.edu.br

Roberto Sanches Mubarac Sobrinho Universidade do Estado do Amazonas, Brasil ORCID: https://orcid.org/0000-0003-4893-0883

ID Lattes: http://lattes.cnpq.br/7931430917921646 Endereço eletrônico: rmubarac@ hotmail.com

\section{RESUMO}

O objetivo deste artigo é refletir sobre o processo de formação de professores indígenas, tomando como referência o Currículo do Curso de Pedagogia Intercultural Indígena, da Universidade do Estado do Amazonas, no âmbito do Programa Nacional de

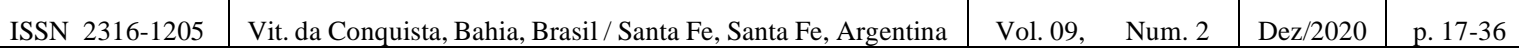


Formação de Professores (Parfor). O curso foi construído num árduo processo dialético, que envolveu a população indígena local, os movimentos sociais, as instituições de ensino, além da participação efetiva dos intelectuais e pesquisadores dessa temática. Foram vários momentos de intensas conversas, discussão e socialização, visando à construção do Projeto do Curso e, consequentemente, do currículo, as quais aconteceram por meio de assembleias com os professores indígenas dos povos Kanamari, Marubo, Matis e Matsés, nos anos de 2014, 2015 e 2016, bem como a partir das discussões entre as diferentes instituições parceiras: Fundação Nacional do índio (Funai), Secretaria Municipal de Educação (Semed) Atalaia do Norte e Universidade do Estado do Amazonas (UEA). A metodologia utilizada foi a análise documental, na perspectiva qualitativa, que visou historicizar e refletir sobre o processo de construção do currículo do curso.

PALAVRAS-CHAVE: Formação de Professores; Currículo; Resistência; Interculturalidade.

\title{
RESUMEN
}

El propósito de este artículo es reflexionar sobre el proceso de formación de docentes indígenas, tomando como referencia el Currículo del Curso de Pedagogía Intercultural de la Universidad Estadual de Amazonas, en el ámbito del Programa Nacional de Formación Docente (Parfor). El curso se construyó sobre un arduo proceso dialéctico, que involucró a la población indígena local, movimientos sociales, instituciones educativas, además de la participación efectiva de intelectuales e investigadores en este tema. Fueron varios momentos de intensas conversaciones, discusión y socialización, encaminadas a la construcción del Proyecto del Curso y, en consecuencia, el currículo, que se llevó a cabo a través de encuentros con los maestros indígenas de los pueblos Kanamari, Marubo, Matis y Matsés, en 2014 , 2015 y 2016, así como de discusiones entre las diferentes instituciones socias: Fundación Nacional del Indio (Funai), Secretaría de Educación Municipal (Semed) Atalaia do Norte y Universidad Estatal de Amazonas (UEA). La metodología utilizada fue el análisis de documentos, desde una perspectiva cualitativa, que tuvo como objetivo historizar y reflexionar sobre el proceso de construcción del currículo del curso.

PALABRAS-CLAVE: Formación docente; Plan de estudios; Resistencia; Interculturalidad.

\begin{abstract}
The purpose of this article is to reflect on the process of training indigenous teachers, taking as reference the Curriculum of the Indigenous Intercultural Pedagogy Course of the State University of Amazonas, within the scope of Parfor. The course was built
\end{abstract}


on an arduous dialectical process, which involved the local indigenous population, social movements, educational institutions, in addition to the effective participation of intellectuals and researchers on this topic. There were several moments of intense conversations, discussion and socialization aiming the building the Course Project and consequently the curriculum, which took place through meetings with indigenous teachers Kanamari, Marubo, Matis and Mayoruna/Matsés peoples, in the years 2014, 2015 and 2016, as well as from the discussions between the different partner institutions: FUNAI, Municipal Education Secretary-SEMED Atalaia do Norte, São Paulo de Olivença and Amazonas State University / UEA. The used methodology was the documental analysis, in the qualitaty perspective, wich aimed to historicize and reflect about the process of building of the course Curriculum.

KEYWORDS: Teacher Education; Curriculum, Resistance, Interculturality.

\section{INTRODUÇÃO}

O presente artigo tem como objetivo refletir acerca da formação de professores indígenas, tomando-se como escopo central o processo de construção e desenvolvimento do Currículo do Curso de Pedagogia Intercultural Indígena, oferecido no município de Atalaia do Norte, no Vale do Javari, extremo norte do estado do Amazonas, no âmbito do Programa de Formação de Professores da Educação Básica-Parfor, da Universidade do Estado do Amazonas-UEA.

O Estado do Amazonas abriga o maior número de povos e línguas indígenas do Brasil e, por esse motivo, as demandas da educação escolar indígena são complexas e numerosas, destacando-se as relativas à formação de professores e gestores para suas escolas. Nesse cenário, as reflexões aqui apresentadas discutem o currículo do curso de Pedagogia Intercultural Indígena, ofertado pela Universidade do Estado do Amazonas (UEA).

Consideramos importante situar o Vale do Javari nesse contexto, sendo esse um dos territórios com o maior número de povos indígenas isolados, de pouco contato no Brasil e contatos recentes. Em seu relatório de Identificação e Delimitação da Terra Indígena Vale do Javari, Coutinho Jr. (1998, p. 03.) afirma que este território é "uma das partes mais remotas e desconhecidas do território brasileiro na Amazônia.”. Ainda segundo o mesmo autor, a superfície da Terra Indígena Vale do Javari é de 8.457 .000 ha e perímetro de $2.140 \mathrm{Km}$. 
APARTIR DO CURRÍCULO DO CURSO DE PEDAGOGIA INTERCULTURA] INDÍGENA

Abrange áreas banhadas pelos rios Javari, Curuçá, Ituí, Itacoaí e Quixito, além dos altos cursos dos rios Jutaí e Jandiatuba.

Figura 1: Mapa do TEE Vale do Javari

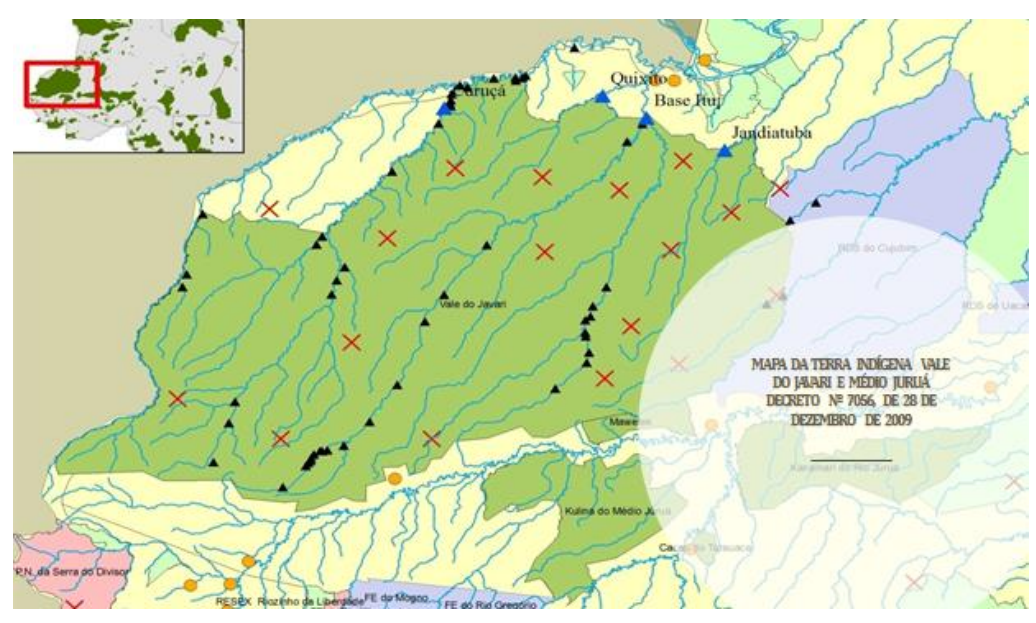

Fonte: Mapa dos Territórios Etnoeducacionais Pactuados. (Slide MEC, 2014)

Com essa contextualização do local onde se desenvolveu o curso, salientamos que o histórico de escolarização desses povos, bem como a implantação de escolas nas aldeias são recentes. Dessa forma, a demanda de formação de professores e a organização de suas escolas, de forma diferenciada, é um ato de resistência política desses povos, o que reverbera na forma como participaram das discussões do currículo e no envolvimento das lideranças nesse processo.

No Curso de Pedagogia Intercultural, todos os acadêmicos são indígenas e $90 \%$ deles já atuam como professores em suas comunidades. Nas turmas, estão presentes 04 povos: Marubo, Matis, Kanamari, Matises. A construção do currículo e o planejamento das práticas educativas, no decorrer do curso, caracterizou-se por amplos diálogos interculturais, tendo em vista a dinâmica da organização dos professores nas comunidades, como passaremos a discutir a seguir.

\section{Formação de professores indígenas no Brasil como práticas de resistência}

Consolidar o processo de formação de professores indígenas no Brasil para atuarem nas escolas de suas aldeias é, sem dúvida, o principal desafio que impulsiona o papel que a escola desempenha e irá desempenhar em cada comunidade. Os muitos cursos e programas de formação de professores indígenas, em andamento em diferentes regiões do país, como aponta 
APARTIR DO CURRÍCULO DO CURSO DE PEDAGOGIA INTERCULTURA] INDÍGENA

a literatura da área, vêm demonstrando bons resultados e permitindo a construção de bases pedagógicas e políticas, que possam garantir a efetiva realização da educação escolar indígena diferenciada, já definida desde a Constituição Federal de 1988.

Nesse sentido, o que se acompanha, em todo o Brasil, é o crescimento e o aprofundamento de uma nova forma de se pensar a formação de professores, na qual os indígenas, pertencentes a suas comunidades, são por elas referendados para assumirem o protagonismo da docência das escolas indígenas, o que consolida uma luta de muitos anos para que os professores dessas escolas sejam todos indígenas e com vínculo à comunidade na qual a escola está inserida.

Assim, a educação escolar indígena, como conhecemos atualmente, delineada a partir das noções "intercultural, comunitária, específica e diferenciada", sempre foi um campo de atuação político-pedagógica que, desde o início do processo de colonização no Brasil, enfrentou diversas fases e em termos de política pública educacional tem se configurado como um instrumento de luta e resistência dos povos indígenas.

Para se discutir sobre a formação de professores indígenas, adotamos uma reflexão acerca dos instrumentos normativos que representam alguns referenciais importantes para compreendermos os processos que envolvem a formação dos professores, a partir da experiência da construção do Currículo do Curso de Pedagogia Intercultural Indígena, ofertado pela UEA.

Sob o ponto de vista legal, a Constituição Federal de 1988 dispõe sobre a educação indígena, oferecendo a garantia do ensino escolar indígena na modalidade bilíngue, afirmando no art. 210, parágrafo $2^{\circ}$, que "O ensino fundamental regular será ministrado em língua portuguesa, assegurada às comunidades indígenas também a utilização de suas línguas maternas e processos próprios de aprendizagem.” (BRASIL, 1988).

Magalhães (2005) compila, a propósito, um conjunto de leis que regem a educação escolar indígena atualmente. Conforme citado por ele, o Decreto n ${ }^{\circ}$. 26, de 04/02/1991, dispõe sobre a educação escolar indígena no Brasil, atribuindo ao Ministério da Educação - MEC a competência de sua oferta, até então de responsabilidade da Funai, além de determinar às secretarias de educação dos estados e municípios responsabilidade conjunta.

A Portaria Interministerial MJ e MEC nº 559 de 16/04/1991, reforçando as disposições da Constituição Federal de 1988, trata da garantia de oferta da educação escolar indígena de qualidade, laica e diferenciada; do ensino bilíngue; da criação de órgãos normativos para o 
APARTIR DO CURRÍCULO DO CURSO DE PEDAGOGIA INTERCULTURA] INDÍGENA

acompanhamento e desenvolvimento da educação indígena; dos recursos financeiros; da formação de professores capacitados; do reconhecimento das instituições escolares; da garantia de continuação dos estudos em escolas comuns quando este não for oferecido nas escolas indígenas; da garantia de acesso ao material didático; da isonomia salarial entre professores índios e não-índios; e da determinação da revisão da imagem do índio, historicamente distorcida, a ser divulgada nas redes de ensino.

Em 1996, a nova Lei de Diretrizes e Bases da Educação Nacional (LDBEN) - Lei ${ }^{\circ}$ 9.394, de 20/12/1996, no seu art. 78, também tratara da oferta do ensino regular para os povos indígenas:

Art. 78. O Sistema de Ensino da União, com a colaboração das agências federais de fomento à cultura e de assistência aos índios, desenvolverá programas integrado de ensino e pesquisa, para oferta de educação escolar bilíngue e intercultural aos povos indígenas, com os seguintes objetivos:

I - Proporcionar aos índios, suas comunidades e povos, a recuperação de suas memórias históricas; a reafirmação de suas identidades étnicas; a valorização de suas línguas e ciências;

I - Garantir aos índios, suas comunidades e povos, o acesso às informações, conhecimentos técnicos e científicos da sociedade nacional e demais sociedades indígenas e não-índias.

No art. 79, a LDBEN dispõe sobre o desenvolvimento dos programas educacionais indígenas:

Art. 79. A União apoiará técnica e financeiramente os sistemas de ensino no provimento da educação intercultural às comunidades indígenas, desenvolvendo programas integrados de ensino e pesquisa.

$\S 1^{\circ}$ Os programas serão planejados com audiência das comunidades indígenas.

$\S 2^{\circ}$ Os programas a que se refere este artigo, incluídos no Plano Nacional da Educação, terão os seguintes objetivos:

I - Fortalecer as práticas socioculturais e a língua materna de cada comunidade indígena;

I - Manter os programas de formação de pessoal especializado, destinado à educação escolar nas comunidades indígenas;

I - Desenvolver currículos e programas específicos, neles incluindo os conteúdos culturais correspondentes às respectivas comunidades;

IV - Elaborar e publicar sistematicamente material didático específico e diferenciado.

Já o Decreto $n^{\circ}$ 6.861, de 27/05/2009, define a organização do sistema educacional indígena no território nacional, determinando a participação da comunidade indígena na 
APARTIR DO CURRÍCULO DO CURSO DE PEDAGOGIA INTERCULTURA] INDÍGENA

organização do sistema de ensino, respeitando sua territorialidade, suas necessidades e especificidades; definindo os objetivos da educação escolar indígena:

I - Valorização das culturas dos povos indígenas e a afirmação e manutenção de sua diversidade étnica;

II - Fortalecimento das práticas socioculturais e da língua materna de cada comunidade indígena;

III - Formulação e manutenção de programas de formação de pessoal especializado, destinados à educação escolar nas comunidades indígenas;

IV - Desenvolvimento de currículos e programas específicos, neles incluindo os conteúdos culturais correspondentes às respectivas comunidades;

$\mathrm{V}$ - Elaboração e publicação sistemática de material didático específico e diferenciado; e

VI - Afirmação das identidades étnicas e consideração dos projetos societários definidos de forma autônoma por cada povo indígena;

A atuação de indígenas como professores e gestores de suas escolas é uma conquista desses povos que emana, dentre outras questões, do direito à educação própria conquistado na Constituição Federal de 1988. As reivindicações por formação de professores indígenas tornaram-se uma luta do movimento desses povos e suas organizações, buscando uma formação específica que contemplasse as características socioculturais de suas comunidades e atendesse aos princípios da escola indígena comunitária, específica, diferenciada e bilíngue.

Nesse particular, as Diretrizes Curriculares Nacionais para a Educação Escolar Indígena na Educação Básica, definidas pela Resolução CNE/CEB nº 5/2012 preceituam que:

Art. $19 \S 1^{\circ}$ Os professores indígenas, no cenário político e pedagógico, são importantes interlocutores nos processos de construção do diálogo intercultural, mediando e articulando os interesses de suas comunidades com os da sociedade em geral e com os de outros grupos particulares, promovendo a sistematização e organização de novos saberes e práticas. (BRASIL, 2012, p. 10).

A importância do professor indígena na escola é destacada como a interlocução na construção do diálogo intercultural com a sociedade envolvente e os conhecimentos universais, como também na manutenção dos conhecimentos e modos próprios de organização do seu povo. Sendo assim, constitui-se também num ato político de resistência às formas de colonização, ao racismo estrutural, presente em nossa sociedade, e às demais formas de exclusão que lhes são impostas. 
APARTIR DO CURRÍCULO DO CURSO DE PEDAGOGIA INTERCULTURA] INDÍGENA

Sobre essa questão, o parecer do Conselho Nacional de Educação/CP n. 6/2014 relata na sua introdução que:

Segundo dados da CGEEI/MEC, de 2005 a 2011 estiveram em formação nos cursos de licenciaturas 2.620 (dois mil seiscentos e vinte) professores indígenas em 20 (vinte) IES que ofertaram 23 (vinte e três) cursos em 14 (catorze) estados da federação. A heterogeneidade destas experiências se traduziu em diferentes resultados institucionais, acarretando, por exemplo, modos distintos de organização dos currículos, dos tempos e dos espaços de realização dos cursos, bem como formas diferenciadas de relacionamento entre as instituições formadoras e o movimento indígena. (BRASIL, 2014. p. $5-6)$.

Como afirma o texto, as experiências das instituições formadoras têm sido gestadas no seu próprio desenvolvimento, estando, dessa forma, ainda em andamento. Nesse processo, a reflexão sobre o que já foi produzido ou está em desenvolvimento é uma forma de trazer às discussões mais amplas as políticas de formação para esse magistério intercultural, bem como promover a escuta desses movimentos de resistência que demandam essa formação.

De forma mais específica, e já entendendo a formação no contexto do Ensino Superior, a Resolução CNE 01/2015 instituiu Diretrizes Curriculares Nacionais para a Formação de Professores Indígenas em cursos de Educação Superior e de Ensino Médio onde orienta que:

\begin{abstract}
Art. $4^{\circ}$ A formação inicial de professores indígenas deverá ser realizada em cursos específicos de licenciaturas e pedagogias interculturais e, quando for o caso, em outros cursos de licenciatura, programas especiais de formação pedagógica e aproveitamento de estudos ou, ainda, excepcionalmente, em outros cursos destinados ao magistério indígena de Nível Médio nas modalidades normal ou técnica. (BRASIL, 2015, p. 2).
\end{abstract}

Segundo esta Resolução, a formação de professores indígenas deverá ocorrer em nível superior e, excepcionalmente, em nível médio, na modalidade normal, em cursos específicos de magistério indígena. $\mathrm{O}$ documento salienta que esses cursos devem formar "para atuar na Educação Escolar Indígena com vistas ao exercício integrado da docência, da gestão e da pesquisa assumida como princípio pedagógico" (BRASIL, 2015, p. 1).

Nesse sentido, as propostas curriculares para a formação de professores indígenas, em atenção às especificidades da Educação Escolar Indígena, devem ser construídas com base na pluralidade de ideias e concepções pedagógicas, apresentando a flexibilidade necessária ao respeito e à valorização das concepções teóricas e metodológicas de ensino e aprendizagem de 
APARTIR DO CURRÍCULO DO CURSO DE PEDAGOGIA INTERCULTURA] INDÍGENA

cada povo e comunidade indígena. Sob essa perspectiva, apresentaremos nossas reflexões acerca do Currículo do Curso de Pedagogia Intercultural indígena, destacando os processos históricos e metodológicos de sua construção.

\section{A Construção do Currículo do Curso de Pedagogia Intercultural Indígena}

No que tange ao campo teórico, o currículo é uma argumentação abstrata, que articula visões e vozes de atores de todas as matrizes teóricas e baliza discursos produzidos em distintos territórios de conhecimento (MACEDO, 2017). A noção de currículo tornou-se "muitas" e na atualidade abrange múltiplas significações, conforme é possível analisar nos textos dos curriculistas contemporâneos. As contribuições de Lopes e Macedo (2011); Moreira (1997); Silva (1999), apontam a polissemia presente no termo, que resulta das diferentes interpretações teóricas no qual o termo currículo é disputado e interpretado.

Nessa perspectiva, planejar a construção de um currículo para formação de professores indígenas aponta na direção de pensá-lo para além da concepção, seleção, organização e elenco de disciplinas, mesmo que em algum momento sejam descritos componentes curriculares, nomenclaturas, eixos de formação. Assim, este texto busca deslocar a reflexão no sentido de avançar para a ideia de que, nessa construção, foi possível a criação de um espaço-tempo de fronteira entre culturas.

Sobre essa questão, Bhabha (2007, p. 241) apresenta a questão cultural em outra perspectiva, pontuando-a como a enunciação da diferença cultural, ou seja, “o que é signifícado por cultura" em sua complexidade. Dessa forma apresentamos a cultura como prática discursiva e de enunciação.

O enunciativo é um processo mais dialógico que tenta rastrear deslocamentos e realinhamentos que são resultado de antagonismos e articulações culturais - subvertendo a razão do momento hegemônico e recolocando lugares híbridos, alternativos de negociação cultural. (BHABHA, 2007, p. 248)

Entendendo a enunciação para além da ideia da fala de alguém, como espaço de reelaboração de sentidos que se dá em meio às relações estabelecidas entre os sujeitos, dialogando com o autor, podemos afirmar que a cultura, enquanto um processo enunciativo, 
APARTIR DO CURRÍCULO DO CURSO DE PEDAGOGIA INTERCULTURA] INDÍGENA

possibilita que as múltiplas ações do cotidiano, desenvolvidas por sujeitos, formam significados partilhados por grupos e configuram-se como relações culturais.

Caminhando na perspectiva de que os grupos partilham múltiplos significados, essa experiência de formação ofertou 2 (dois) cursos, o primeiro teve início em julho de 2014, no município de São Paulo de Olivença, situado no Alto Solimões; e o segundo em junho de 2016, no município de Atalaia do Norte, localizado no Vale do Javari, sendo este último nosso objeto de discussão.

É importante elencar que, apesar da mesma nomeação, os dois cursos são distintos ${ }^{\mathrm{i}}$, pois se diferenciam tanto na definição dos componentes curriculares, quanto no aprofundamento das propostas formativas, nas abordagens teórico-metodológicas descritas para o desenvolvimento da experiência curricular. Essa "conversa complicada", como bem pontua Pinar (2009) permitiu, além da articulação interinstitucional, a criação de um grupo multidisciplinar com professores das diferentes áreas do conhecimento em profundo diálogo com as lideranças e professores indígenas, oportunidade em que a circulação de múltiplas visões, possibilitaram um exercício de elaboração cultural e social.

O currículo materializado no Projeto Pedagógico do Curso (PPC) apresenta-se como resultado de momentos de discussão e construção de saberes e práticas que envolveram a Universidade, as comunidades indígenas, além das demais instituições numa perspectiva que enfatizasse o trabalho de alfabetização nas línguas indígenas e na produção de material didático para as escolas indígenas.

Esse currículo foi bastante discutido até que se chegasse à proposta visto que a metodologia de trabalho foi organizada desde as consultas prévias aos povos indígenas, mecanismo garantido na Convenção 169. Como já mencionado, essa última proposta amadureceu a partir das questões vivenciadas no desenvolvimento do curso e de uma sistemática mais elaborada nas discussões.

A proposta e a matriz curricular foram debatidas antes e durante o andamento do curso, assim os professores indígenas foram expondo seus anseios sobre os componentes curriculares, sobre os diferentes conhecimentos e espaços de aprendizagem, além de se desafiar enquanto criadores do currículo em que estavam se formando. Como propõe Fleuri (2006, p. 497) "tratase do desafio de se respeitar as diferenças e de integrá-las em uma unidade que não as anule, mas que ative o potencial criativo e vital na conexão entre diferentes agentes e entre seus respectivos contextos".

\begin{tabular}{l|l} 
Revista RBBA & Revista Binacional Brasil Argentina
\end{tabular} 
APARTIR DO CURRÍCULO DO CURSO DE PEDAGOGIA INTERCULTURA] INDÍGENA

A organização curricular do Curso de Pedagogia Intercultural Indígena foi constituída em consonância com a Resolução $\mathrm{N}^{\circ}$ 1, de 7 de janeiro de 2015, em três eixos de formação: Eixo I. Conhecimentos Básicos para Introdução ao Ensino Superior; Eixo II. Letramento Alfabetização e Infâncias em Contextos Indígenas; Eixo III. Didática e Metodologias de Ensino e Aprendizagens na Escola Indígena.

Quadro 01: Matriz curricular

\begin{tabular}{|c|c|}
\hline $\begin{array}{l}\text { EIXOS DOS CAMPOS DE } \\
\text { CONHECIMENTO }\end{array}$ & $\begin{array}{l}\text { COMPONENTES CURRICULARES CONSTITUÍDOS A PARTIR } \\
\text { DOS EIXOS }\end{array}$ \\
\hline \multirow[t]{5}{*}{$\begin{array}{c}\text { Eixo I. Conhecimentos } \\
\text { Básicos para Introdução ao } \\
\text { Ensino Superior } \\
\end{array}$} & Português para fins específicos I \\
\hline & Português para fins específicos II \\
\hline & Fundamentos de Ciências Biológicas \\
\hline & Fundamentos de Ciências Exatas \\
\hline & Fundamentos de Ciências Sociais \\
\hline \multirow{20}{*}{$\begin{array}{c}\text { Eixo II. Letramento } \\
\text { Alfabetização e Infâncias em } \\
\text { Contextos Indígenas. }\end{array}$} & Noções de Fonética e Fonologia e Normatização Ortográfica \\
\hline & História dos Povos Indígenas do Vale do Javari \\
\hline & Filosofia e Pensamento Indígena \\
\hline & Fundamentos da Educação Indígena e Educação Escolar Indígena \\
\hline & História Brasileira e Amazônica \\
\hline & Morfologia e Sintaxe das Línguas Indígenas \\
\hline & Sintaxe das Línguas Indígenas \\
\hline & Normalização Ortográfica das Línguas Indígenas \\
\hline & Letramento e Alfabetização na Escola Indígena I \\
\hline & Letramento e Alfabetização na Escola Indígena II \\
\hline & Letramento e Alfabetização na Escola Indígena III \\
\hline & Letramento e Alfabetização na Escola Indígena IV \\
\hline & Infância Indígena e Escola Indígena \\
\hline & Elaboração de Materiais Didáticos para o Ensino de Línguas \\
\hline & Metodologia do Ensino de Língua Portuguesa como Língua Adicional I \\
\hline & $\begin{array}{c}\text { Tópicos Especiais V: Mapeamento do uso social das Línguas indígenas } \\
\text { nas comunidades do Vale do Javari }\end{array}$ \\
\hline & $\begin{array}{c}\text { Tópicos Especiais I: Levantamento Histórico das Comunidades Indigenas } \\
\text { do Vale do Javari }\end{array}$ \\
\hline & $\begin{array}{c}\text { Tópicos Especiais II: Expressões Culturais das Comunidades Indígenas } \\
\text { do Vale do Javari }\end{array}$ \\
\hline & $\begin{array}{l}\text { Tópicos Especiais III: Organização das Sociedades Indígenas do Vale do } \\
\text { Javari }\end{array}$ \\
\hline & $\begin{array}{c}\text { Tópicos Especiais IV: Produções de vida nas comunidades indígenas no } \\
\text { Vale do Javari }\end{array}$ \\
\hline
\end{tabular}



APARTIR DO CURRÍCULO DO CURSO DE PEDAGOGIA INTERCULTURA] INDÍGENA

\begin{tabular}{|c|c|}
\hline & $\begin{array}{l}\text { Tópicos Especiais VI: Trabalho docente nas comunidades indígenas do } \\
\text { vale do Javari com enfase nos processo de alfabetização I - TCC }\end{array}$ \\
\hline $\begin{array}{l}\text { Eixo III. Didática, } \\
\text { Metodologias de Ensino e }\end{array}$ & $\begin{array}{l}\text { Tópicos Especiais VII: Trabalho docente nas comunidades indígenas do } \\
\text { vale do Javari com enfase nos processos de letramento e alfabetização II } \\
- \text { TCC }\end{array}$ \\
\hline $\begin{array}{l}\text { Aprendizagens e Práticas na } \\
\text { Escola Indígena }\end{array}$ & $\begin{array}{l}\text { Tópicos Especial VIII: Seminário de Socialização do Trabalho de } \\
\text { Conclusao de Curso }\end{array}$ \\
\hline & Aprendizagem em Contextos Indígenas \\
\hline & Pesquisa em Educação: planejamento e sistematização \\
\hline & Organização do Trabalho Pedagógico na Escola Indígena \\
\hline & Direitos Indígenas e Políticas Públicas para a Educação Escolar Indígena \\
\hline & Mitologia dos povos indígenas do Vale do Javari \\
\hline & Artes na Educação Escolar Indígena I \\
\hline & Artes na Educação Escolar Indígena II \\
\hline & Currículo e Educação Escolar Indígena \\
\hline & $\begin{array}{l}\text { Avaliação na Educação Infantil e Anos Iniciais do Ensino Fundamental } \\
\text { na Escola Indígena }\end{array}$ \\
\hline & Escolas Indígenas: Produções Cotidianas \\
\hline & Didática Intercultural \\
\hline & $\begin{array}{l}\text { História na Educação Infantil e Anos Iniciais do Ensino Fundamental na } \\
\text { Escola Indígena I }\end{array}$ \\
\hline & $\begin{array}{l}\text { História na Educação Infantil e Anos Iniciais do Ensino Fundamental na } \\
\text { Escola Indígena II }\end{array}$ \\
\hline & $\begin{array}{c}\text { Etnomatemática na Educação Infantil e Anos Iniciais do Ensino } \\
\text { Fundamental na Escola Indígena I }\end{array}$ \\
\hline & $\begin{array}{c}\text { Etnomatemática na Educação Infantil e Anos Iniciais do Ensino } \\
\text { Fundamental na Escola Indígena II }\end{array}$ \\
\hline & Estágio Supervisionado I \\
\hline & Estágio Supervisionado II \\
\hline & Estágio Supervisionado III \\
\hline & Estágio Supervisionado IV \\
\hline & $\begin{array}{c}\text { Geografia e Territorialidade na Educação Infantil e Anos Iniciais do } \\
\text { Ensino Fundamental na Escola Indígena I }\end{array}$ \\
\hline & $\begin{array}{c}\text { Geografia e Territorialidade na Educação Infantil e Anos Iniciais do } \\
\text { Ensino Fundamental na Escola Indígena II }\end{array}$ \\
\hline & $\begin{array}{c}\text { Etnociências da Natureza na Educação Infantil e Anos Iniciais do Ensino } \\
\text { Fundamental na Escola Indígena I }\end{array}$ \\
\hline & $\begin{array}{c}\text { Etnociências da Natureza na Educação Infantil e Anos Iniciais do Ensino } \\
\text { Fundamental na Escola Indígena II }\end{array}$ \\
\hline & Metodologia do Ensino de Língua Portuguesa como Língua Adicional II \\
\hline & Educação de Jovens e Adultos \\
\hline & Língua Brasileira de Sinais - LIBRAS \\
\hline & Educação Especial \\
\hline & Peradigmas em Educação: Perspectivas Inivadoras na Amazônia \\
\hline
\end{tabular}

Fonte: PPC do curso de Pedagogia Intercultural Indígena de Atalaia do Norte/2019

No primeiro eixo intitulado "Conhecimentos Básicos para Introdução ao Ensino Superior", os componentes curriculares "fazem referência aos conteúdos que subsidiam o acesso do professor indígena ao Ensino Superior" (UNIVERSIDADE DO ESTADO DO 
APARTIR DO CURRÍCULO DO CURSO DE PEDAGOGIA INTERCULTURA] INDÍGENA

AMAZONAS, 2019, p. 60). Esses componentes curriculares possibilitaram momentos de interlocução com alguns conhecimentos, visto que, para todos os indígenas, essa era a primeira vez num curso de ensino superior.

No segundo eixo intitulado "Letramento Alfabetização e Infâncias em Contextos Indígenas", os componentes curriculares "enfatizam a formação do professor indígena que atua nos anos escolares da educação básica que se dedicam ao ensino da leitura e escrita"( UNIVERSIDADE DO ESTADO DO AMAZONAS, 2019, p. 61). Além das disciplinas de Letramento e Alfabetização, outro ponto muito discutido nesse eixo foram as questões sobre infância indígena e seus processos comunitários.

No terceiro eixo intitulado "Didática e Metodologias de Ensino e Aprendizagens na Escola Indígena", os componentes curriculares procuraram a "promoção de diálogos interculturais entre os conhecimentos, saberes e experiências" (UNIVERSIDADE DO ESTADO DO AMAZONAS, 2019, p. 61). Esse eixo buscou a articulação dos espaços formativos, além da valorização dos processos próprios de aprendizagem comunidade visando à construção de materiais específicos para a escola indígena.

Outro momento importante na construção do currículo foi o desenvolvimento das pesquisas sobre as culturas e modos de viver das comunidades do Vale do Javari/AM. As atividades elaboradas por meio da Pedagogia da Alternância possibilitaram a sustentação dos componentes curriculares de Tópicos Especiais ${ }^{\mathrm{ii}}$ e Estágio Supervisionado que fundamentou a construção do Trabalho de Conclusão de Curso.

Conforme o Projeto Pedagógico do Curso (UNIVERSIDADE DO ESTADO DO AMAZONAS, 2019), a Pedagogia da Alternância ocorreu em momentos distintos de ensino e aprendizagem, no caso do curso em dois momentos: O Tempo Universidade (TU) e o Tempo Comunidade (TC). O Tempo Universidade (TU) diz respeito às etapas presenciais do Curso, momento em que foram trabalhados os componentes curriculares no Curso na cidade de Atalaia do Norte/AM. O Tempo Comunidade (TC) diz respeito ao momento em que os professores indígenas desenvolveram pesquisas em suas comunidades, por meio das disciplinas de Tópicos Especiais.

A articulação desses dois Tempos foi fundamental para garantir o êxito do Curso, uma vez que esses momentos possibilitaram a articulação de um currículo de formação de professores voltado para a realidade indígena local, garantindo-se uma formação articulada ao seu espaço de atuação.

Revista RBBA $\mid$ Revista Binacional Brasil Argentina 
APARTIR DO CURRÍCULO DO CURSO DE PEDAGOGIA INTERCULTURA] INDÍGENA

Outro ponto abordado durante o curso foi como o trabalho com os professores do Vale do Javari das etnias Kanamari, Marubo, Matsés e Matis representou a reflexão sobre os processos de constituição das línguas indígenas, pois desde o início houve acompanhamento do linguista especialista em línguas indígenas da família Katukina e Pano, onde as atividades foram extremante detalhadas e discutidas.

O gráfico abaixo demonstra a ênfase do curso no trabalho com as línguas, sendo que $32.1 \%$ do total do curso dedicou-se a essa questão, seja da língua própria, seja da língua portuguesa como língua adicional, envolvendo os processos de alfabetização e letramento, pesquisa e produção de materiais didáticos.

Figura 2: Gráfico demonstrativo de disciplinas

Total de Disciplina

Disciplinas voltadas para língua

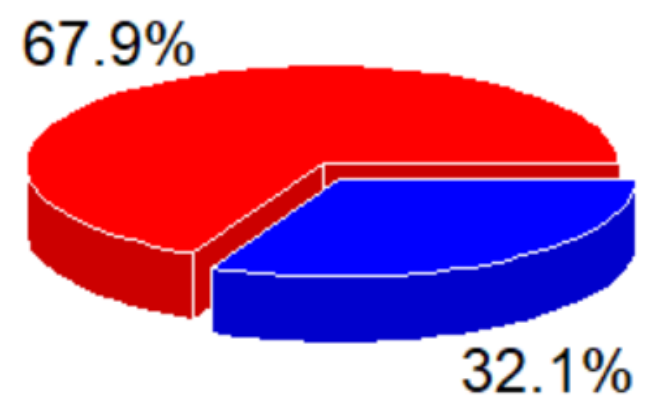

Fonte: Elaborado pelos autores (2020).

Construir um curso em diálogo com os professores indígenas e que considerasse o letramento nas línguas indígenas, pontos que para os acadêmicos era fundamental, exigiu responsabilidade e abertura para pensar um currículo diferenciado de um curso regular de Pedagogia.

Nessa perspectiva, aliás, compreendemos no processo de constituição do currículo que não se tratava de reproduzir um "modelo de currículo de formação dos Cursos de Pedagogia (não indígena)" em um curso de Pedagogia que forma professores indígenas, mas de atentar para as especificidades dessa formação que, inclusive, possui uma nomeação bem específica de Pedagogia Intercultural Indígena, o que se concretizou nos processo pedagógicos do curso. 
APARTIR DO CURRÍCULO DO CURSO DE PEDAGOGIA INTERCULTURA] INDÍGENA

\section{O Currículo do Curso de Pedagogia Intercultural indígena como prática de resistência}

A formação de professores não é algo pronto, acabado. Mesmo quando tratamos da formação inicial, como é o caso do Curso de Pedagogia Intercultural Indígena, é importante refletir que os que adentram esse espaço formativo trazem consigo experiências que antecedem este momento e que se imbricam aos processos de aprendizagem vivenciados no curso.

Tardif (2013, p.19-20) nos afirma que o saber do professor não tem uma única fonte, ele “é plural e também temporal [...] adquirido no contexto de uma história de vida e de uma carreira profissional" refletindo sobre como os professores amalgamam esses saberes que possuem e a forma como fazem essa fusão.

Visando agregar esses saberes ao que se produziu no curso que aqui se reflete, a escrita do memorial analítico constituiu um dos itens elaborados no Trabalho de Conclusão do Curso (TCC). Este memorial objetivou que o professor em formação retomasse seu percurso formativo, suas aprendizagens e experiências, e refletisse sobre elas. Esta reflexão, por sua vez, visou que este professor atentasse para sua formação como um processo não pontual, mas contínuo, no qual se convergiram os diferentes elementos que o constituem como professor, inclusive seu repertório cultural.

Nessa direção, o eixo desenvolvido no curso, tendo a pesquisa como base do trabalho formativo, desenhou-se de forma articulada nas disciplinas Tópicos Especiais, já citadas anteriormente. Esses componentes, orientados no tempo Universidade e construídos no Tempo Comunidade, constituíram-se em pesquisas desenvolvidas pelos acadêmicos sobre a história de seus povos, seus territórios, suas culturas, seus conhecimentos e formas de organização.

Segundo o PPC (UNIVERSIDADE DO ESTADO DO AMAZONAS, 2019, p. 70),

O currículo do curso articula-se por meio da disciplina de Tópicos Especiais que estão atrelados aos períodos de estágio e às atividades desenvolvidas no Tempo Comunidade (TC). Assim, as disciplinas de Tópicos Especiais darão sustentação para as disciplinas dos módulos realizados no Tempo Universidade (TU), as experiências advindas das pesquisas realizadas devem ser valorizadas no curso e contribuírem na discussão das disciplinas realizadas nos módulos no Tempo Universidade.

Destacamos que a realização das pesquisas pelos próprios acadêmicos foi de extrema importância, pois oportunizou a eles e a suas comunidades reavivarem suas histórias, suas memórias e geraram um vasto material que se organizou pedagogicamente para compor o TCC

Revista RBBA Revista Binacional Brasil Argentina 
APARTIR DO CURRÍCULO DO CURSO DE PEDAGOGIA INTERCULTURA] INDÍGENA

e os produtos desenvolvidos no Estágio Supervisionado. A promoção da pesquisa é também uma recomendação da Resolução CNE/CP01/2015 que traz como um dos objetivos dos cursos de formação:

IV - Fomentar pesquisas voltadas para as questões do cotidiano escolar, para os interesses e as necessidades culturais, sociais, étnicas, políticas, econômicas, ambientais e linguísticas dos povos indígenas e de suas comunidades, articuladamente aos projetos educativos dos povos indígenas. (BRASIL, 2015, p. 2)

Nessa perspectiva, ressaltamos que o componente curricular "Estágio Supervisionado" organizado em 04 (quatro) disciplinas, ocupou igualmente um lugar de articulação na matriz curricular do curso. O componente dialogou com os outros componentes curriculares e com os conhecimentos culturais desses povos. No desdobramento das disciplinas, houve a construção de diferentes produções que se reverberaram no trabalho da escola indígena, como: mapas linguísticos, materiais didáticos específicos, subsídios para organização da escola, o próprio memorial e um conjunto de reflexões sobre os princípios da educação escolar indígena a partir do projeto societário de cada povo.

Quadro 2: Organização do Estágio Supervisionado

\begin{tabular}{|l|l|l|}
\hline Disciplina & Período & Objetivo \\
\hline $\begin{array}{l}\text { Estágio } \\
\text { Supervisionado I }\end{array}$ & $5^{\circ}$ & $\begin{array}{l}\text { Refletir sobre a escola indígena e as trajetórias formativas visando o } \\
\text { fortalecimento da identidade docente o compromisso social e político do } \\
\text { professor indígena. }\end{array}$ \\
\hline $\begin{array}{l}\text { Estágio } \\
\text { Supervisionado II }\end{array}$ & 6 & $\begin{array}{l}\text { Realizar uma pesquisa/ levantamento do uso social da língua indígena nos } \\
\text { diferentes espaços da comunidade, da escola e aprofundar o conhecimento } \\
\text { sobre a língua indígena visando o desenvolvimento de atividades de intervenção } \\
\text { da língua indígena nestes dois espaços, ou seja, na comunidade e na escola. }\end{array}$ \\
\hline $\begin{array}{l}\text { Estágio } \\
\text { Supervisionado } \\
\text { III }\end{array}$ & 7 & $\begin{array}{l}\text { Planejar atividades interdisciplinares para a escola indígena a partir da produção } \\
\text { de materiais didáticos e desenvolvimento de sequências didáticas com a língua } \\
\text { indígena para o ensino e aprendizagem em escola indígena. }\end{array}$ \\
\hline $\begin{array}{l}\text { Estágio } \\
\text { Supervisionado } \\
\text { IV }\end{array}$ & $\begin{array}{l}\text { Compreender como a escola indígena pode ser organizada a partir da Gestão } \\
\text { compartilhada e da participação comunitária. }\end{array}$ \\
\hline
\end{tabular}

Fonte: Elaborado pelos autores (2020), a partir do PPC do curso.

A organização do Estágio Supervisionado demonstrada no quadro 2, permite-nos observar a articulação dos objetivos de cada componente, remetendo-nos aos conhecimentos Revista RBBA Revista Binacional Brasil Argentina 
APARTIR DO CURRÍCULO DO CURSO DE PEDAGOGIA INTERCULTURA] INDÍGENA

trabalhados durante o curso. Estes, por sua vez, se articulam com as questões socioculturais e linguísticas seguindo um caminho pedagógico voltado à escola indígena. Dessa forma, toda a produção realizada pelos acadêmicos durante o curso materializou-se no TCC como parte integrante do percurso formativo desenvolvido no currículo.

\section{CONSIDERAÇÕES FINAIS}

Estamos vivendo um tempo de retirada de direitos de forma geral e, muito especificamente, o direito dos povos indígenas a uma educação escolar diferenciada tem ficado à margem da política em curso. Essa exclusão e o racismo estrutural, tão intensos nos últimos tempos, desafiam os povos indígenas e os indigenistas a buscarem formas de resistência.

Resistir sempre foi uma realidade para os povos originários durante todo o período de colonização e de integração forçada à sociedade nacional. Uma estratégia de resistência desses povos, tem sido a construção de uma escola ressignificada e com feição própria. Mas uma escola não se consolida sem professores. Nesse debate, a formação de professores indígenas ganha importante realce no que diz respeito à proposta de cursos que considerem suas especificidades e realidades sociolinguísticas.

Nessa direção, as discussões aqui apresentadas materializam-se como reflexão do coletivo que experienciou/experiencia a formação no curso de Pedagogia Intercultural Indígena e sua busca pela construção de um currículo que se diferenciou de um curso não indígena. Todavia, compreendemos que nas negociações travadas durante esse percurso houve acertos e apresentaram-se desafios que não conseguimos superar de forma plena.

A avaliação contínua do curso realizado em São Paulo de Olivença, objeto de estudo de tese conforme a nota de rodapé 4 , beneficiou a construção do currículo do curso de Atalaia do Norte oportunizando a ênfase numa política linguística mais efetiva e no acompanhamento do Tempo Comunidade priorizando as pesquisas nas comunidades.

Somos cientes de que todo trabalho precisa e deve ser avaliado, criticado, para que possa amadurecer e se aperfeiçoar para que novas iniciativas nesse sentido possam ser realizadas com outros povos, e em outras regiões do Amazonas ou de outros estados.

Certamente o curso não conseguiu alcançar todas as discussões e reflexões realizadas e sempre ficam desafios ainda a serem superados. Contudo, compreendemos que um curso não se esgota em si mesmo e gera novas demandas para todos os envolvidos, seja a universidade, 
APARTIR DO CURRÍCULO DO CURSO DE PEDAGOGIA INTERCULTURA] INDÍGENA

os acadêmicos, as aldeias e as próprias secretarias municipais de educação. Nesse movimento, que envolve diferentes sujeitos, novas discussões são levantadas acerca das políticas públicas no que tange a esta questão.

\section{REFERÊNCIAS}

BHABHA, Homi K. O local da cultura. Belo Horizonte: Editora da UFMG, 2007.

BRASIL. Constituição (1988). Constituição da República Federativa do Brasil: promulgada em 5 de outubro de 1988.

. Lei n ${ }^{\circ}$ 9.394/ 96. Lei de Diretrizes e Bases da Educação Nacional. Diário oficial da União, Brasília, 23 de dezembro de 1996.

. Resolução CEB n 3, de 10 de novembro de 1999. Fixa Diretrizes Nacionais para o funcionamento das escolas indígenas e dá outras providências. Seção 1. Pag.19.

Parecer CNE $n^{\circ}$ 09/2001. Diretrizes Curriculares Nacionais para a Formação de Professores da Educação Básica, em nível superior, curso de licenciatura, de graduação plena. Publicado no Diário Oficial da União de 18/1/2002, Seção 1, p. 31.

Parecer CNE n ${ }^{\circ}$ 28/2001. Dá nova redação ao Parecer CNE/CP 21/2001, que estabelece a duração e a carga horária dos cursos de Formação de Professores da Educação Básica, em nível superior, curso de licenciatura, de graduação plena. Publicado no Diário Oficial da União de 18/1/2002, Seção 1, p. 31.

Decreto $n^{\circ}$ 6.861, de 27 de maio de 2009. Dispõe sobre a Educação Escolar Indígena, define sua organização em territórios etnoeducacionais, e dá outras providências.

. Parecer CNE/CEB n 13/2012. Diretrizes Curriculares Nacionais para a Educação Escolar Indígena. Publicado no D.O.U. de 15/6/2012, Seção 1, Pág. 18.

Resolução CNE/CEB nº 5, de 22 de junho de 2012. Define Diretrizes Curriculares Nacionais para a Educação Escolar Indígena na Educação Básica. Brasília: Diário Oficial da União, DF, Seção I, p. 7, jun. 2012.

Parecer do Conselho Nacional de Educação/CP n ${ }^{\circ}$ 6/2014. Diretrizes Curriculares Nacionais para a Formação de Professores Indígenas. Aprovado em 02/04/2014 (homologado em Despacho do Ministro, publicado no D.O.U. de 31/12/2014, Seção 1, p. 85).

Resolução CNE/CP n ${ }^{\circ}$ 1/2015. Institui Diretrizes Curriculares Nacionais para a Formação de Professores Indígenas em cursos de Educação Superior e de Ensino Médio e dá outras providências. Diário Oficial da União, Brasília, 8 de janeiro de 2015 - Seção 1 pp. 11-12. 
APARTIR DO CURRÍCULO DO CURSO DE PEDAGOGIA INTERCULTURA] INDÍGENA

COUTINHO JR., Walter. Relatório de Identificação e Delimitação da Terra Indígena Vale do Javari. Brasília: FUNAI, 1998.

FLEURI, Reinaldo Matias. Políticas da diferença: para além dos estereótipos na prática educacional. Educ. Soc., Campinas, vol. 27, n. 95, p. 495-520, maio/ago. 2006. Disponível em http://www.cedes.unicamp.br Acesso em 16/06/2020.

LOPES, Alice Casimiro; MACEDO, Elizabeth. Teorias do Currículo. São Paulo: Cortes, 2011.

LUCIANO, Gersem José dos Santos. Relatório técnico diagnóstico e avaliação dos formulários e da metodologia do censo Inep referente à questão indígena. 2015. Disponível em <http://www.mpf.mp.br/atuacao-tematica/ccr6/dados-da-atuacao/projetos/mpf-em-defesada-escola-indigena-1/docs_relatorios-tecnicos/relatorio-diagnostico-censo-escolas-indigenasinep-vf.pdf>. Acesso em 16/06/2016.

MACEDO, Elizabeth. Mas a escola não tem que ensinar?: Conhecimento, reconhecimento e alteridade na teoria do currículo. Currículo sem Fronteiras, v. 17, n. 3, p. 539-554, set./dez.2017. Disponível

em: <www.curriculosemfronteiras.org/vol17iss3articles/macedo.pdf>. Acesso em 20.ago.2020.

Currículo como enunciação: Diálogos com os sentidos de Currículo no Brasil. Versão em português do texto publicado em Pinar, W. (2011). Curriculum Studies in Brazil. New York: Palgrave McMillan.

MAGALHÃES, Edvard Dias (Org.). Legislação Indigenista Brasileira e Normas Correlatas. 3.ed. Brasília: FUNAI/CGDOC, 2005.

MOREIRA, A. F. (Org.). Currículo: questões atuais. Campinas: Papirus, 1997.

SILVA, Tomaz Tadeu. Documentos de identidade. 2. ed. Autêntica: Belo Horizonte, 1999.

PINAR, William F. Multiculturalismo Malicioso. Currículo sem Fronteiras, v.9, n.2, pp.149168, Jul/Dez 2009.

TARDIF, M. Saberes docentes e formação profissional. 15. ed. Petrópolis: Vozes, 2013.

UnIVERSIDADE DO ESTADO DO AMAZONAS. Projeto Pedagógico do Curso de Pedagogia Intercultural Indígena. 2019. 

APARTIR DO CURRÍCULO DO CURSO DE PEDAGOGIA INTERCULTURA] INDÍGENA

\title{
Notas
}

\begin{abstract}
${ }^{i}$ A Tese de Doutorado de Celia Aparecida Bettiol intitulada "A formação de professores indígenas na Universidade do Estado do Amazonas: avanços e desafios", reflete detalhadamente sobre o Curso de Pedagogia Intercultural Indígena, ofertado no Alto Solimões, que foi referência para a construção do currículo aqui analisado.

ii Foram 08 (oito) momentos no total: Tópicos Especiais I: Levantamento Histórico das Comunidades Indígenas do Vale do Javari; Tópicos Especiais II: Expressões Culturais das Comunidades Indígenas do Vale do Javari, Tópicos Especiais III: Organização das Sociedades Indígenas do Vale do Javari, Tópicos Especiais IV: Produções de vida nas comunidades indígenas do Vale do Javari, Tópicos Especiais V: Mapeamento do uso social das Línguas indígenas nas comunidades do Vale do Javari; Tópicos Especiais VI: Trabalho docente nas comunidades indígenas do vale do Javari com ênfase nos Processos de Letramento e Alfabetização I - TCC; Tópicos VII: Trabalho docente nas comunidades indígenas do Vale do Javari com ênfase nos processos de Letramento e Alfabetização II (TCC), Tópicos Especial VIII: Seminário de Socialização do Trabalho de Conclusão de Curso. Projeto Pedagógico do Curso (2019).
\end{abstract}

